\title{
TOTAL THYROIDECTOMY FOR HEART FAILURE: AN UNUSUAL CASE
}

\author{
BY \\ W. R. TROTTER AND K. C. EDEN \\ From the Medical and Surgical Units, University College Hospital \\ Received May 15, 1941
}

Congestive cardiac failure associated with thyrotoxicosis is almost always relieved by sub-total thyroidectomy. It is probable that the improvement in the cardiac condition can be attributed to two distinct factors: first, to the removal of a direct toxic action of the thyroid secretion on the heart, and, secondly, to the removal of the burden of an augmented circulation rate that the increased metabolism of thyrotoxicosis places upon the heart. The direct effect of the thyroid on the heart is evident in the common association of auricular fibrillation with thyrotoxicosis and in the frequency with which normal rhythm is restored in such cases after sub-total thyroidectomy. The close connection between thyrotoxicosis and auricular fibrillation is also seen in the common occurrence of the latter in the first two days after thyroidectomy -a time when all the manifestations of thyrotoxicosis are generally at their height.

The effect of thyroidectomy in sparing the work of the heart has been most fully demonstrated by the work of Blumgart, Levine, Berlin, and their colleagues on total thyroidectomy for non-thyrotoxic heart disease. In a series of papers (summarized by Blumgart et al. 1933) they showed that in the absence of cardiac failure the circulation rate in normal subjects and in cases of thyrotoxicosis and of myxœdema was adjusted in proportion to the metabolic rate. When heart failure is present, however, this relationship breaks down, so that in the ordinary cases of congestive heart failure, although the basal metabolic rate is normal, the circulation rate is no greater than in a case of myxœdema without heart failure. Similarly, in cases of thyrotoxicosis with heart failure, the circulation rate is less than in other such cases without heart failure. On the basis of these findings, they put forward the practical suggestion that in congestive cardiac failure the lost equilibrium between circulation rate and metabolic rate could be restored by reducing the latter to the level of the former by total thyroidectomy. Although the measure of success achieved by this therapy is still in dispute, it seems clear from the work of Blumgart and his colleagues, and those who have repeated it, that cases of congestive cardiac failure can sometimes be improved by total thyroidectomy; and that such improvement, 
when it occurs, is brought about by diminishing the work the heart has to do rather than by increasing its capacity to do it.

We are reporting here the case of a patient in whom the removal of a normal thyroid gland was followed not only by the relief of cardiac failure but also by the disappearance of auricular fibrillation. It seems to us improbable that the abolition of auricular fibrillation can be attributed merely to the lowering of the metabolic rate, and we feel bound to postulate in this patient a direct action of the normal thyroid gland on the heart. However it was brought about, there can be no doubt that total thyroidectomy proved to be a most successful form of therapy, and one which might be worth trying in similar cases.

The patient was a man, aged 51, at the time of operation. He was first admitted to University College Hospital under Dr. Kenneth Harris in 1931, at the age of 43, with a history of breathlessness and swelling of the legs for four weeks. There was no history of rheumatic fever. On admission, he was found to be in congestive cardiac failure; the heart rate was 160-180 and the rhythm regular. A cardiogram showed auricular flutter. He was given digitalis in full doses; the rhythm became normal on the seventh day and the signs of congestive failure then quickly disappeared. $\mathrm{He}$ left hospital with a heart of normal size (orthodiagram) and a regular heart rate of $70-86$.

He then continued at full work (clerical), with occasional attacks of palpitation as the only symptom, until Christmas 1938, when severe palpitation developed, leading to his readmission to hospital four weeks later. He then showed signs of early congestive cardiac failure; the heart rate was $140-170$ and the rhythm grossly irregular. A cardiogram confirmed the diagnosis of auricular fibrillation. There were no signs of valvular damage. He was treated with digitalis; the heart rate was reduced to 84-96 and the signs of congestive failure disappeared; but auricular fibrillation persisted.

He was, however, unable to return to work, and when seen in March 1939 fibrillation was still present and the heart rate was 148. In May 1939, he was readmitted in congestive cardiac failure. The heart rate was 100-140 and auricular fibrillation was still present (confirmed by cardiogram). The heart was considerably enlarged. $\mathrm{He}$ was given digoxin intravenously, and thereafter by mouth. In three weeks the signs of congestive failure had disappeared and the heart rate was 80-96. He was specifically examined at this time for signs of thyrotoxicosis; but none were found.

At this point Dr. Harris advised a total thyroidectomy, and on June 1, 1939, this was performed under local anæsthesia by Mr. Julian Taylor. The post-operative course was uneventful, except for the occurrence of attacks of tetany on the eighth, tenth, and thirteenth days; these were easily controlled by injections of calcium gluconate and by calciferol by mouth. On the thirteenth day after operation the heart returned to normal rhythm (confirmed by cardiogram): this persisted for the rest of his stay in hospital, the rate being 68-76. The heart returned to normal size. He was given no thyroid extract, but calciferol was continued to control the tetany.

When next seen, at the end of July, he was back at full work, and the rhythm was still regular. In September, he was still at work, though somewhat easily tired. The heart rate was 82 , and regular. So far he had had no thyroid extract, and by this time the signs of myxœdema were obvious and appeared to be troubling him. Tab. thyroid sicc. (B.P.) was therefore started in doses of 1.0 gr. daily.

In October the heart was still regular and the rate 84. The dose of thyroid was now increased to $1 \cdot 5 \mathrm{gr}$. daily and maintained at this level till January 8,1940 . In November 1939 he had an attack of tachycardia with irregular rhythm which lasted several hours. In December there were several similar attacks. On January 8 he was seen in an attack of tachycardia; the rhythm being regular and the rate 160 . It was presumed 
that this was paroxysmal auricular flutter, but a cardiogram could not be taken at that time. The thyroid extract was then stopped. A week later he was seen again. This time auricular fibrillation was present, the heart rate being 110. Two days later the heart became regular again and tachycardia ceased. One further attack with irregular heart action occurred on January 21; but it proved to be the last.

By March he had been without thyroid extract for ten weeks and the symptoms of myxœdema had become troublesome again. He was therefore restarted on $0.5 \mathrm{gr}$. daily. This proved to be enough to keep the symptoms of myxœdema at bay. He has been seen at regular intervals for a year since restarting thyroid extract and there has never been any suggestion of a recurrence of the paroxysmal flutter or fibrillation. He has been at full work during this period, and recently has been fire-watching as well. He was anxious to join the Pioneer Corps, but was advised not to do so. $\mathrm{He}$ is able to take a normal amount of exercise without becoming breathless.

The thyroid gland from this patient weighed $20 \mathrm{~g}$., which is within normal limits for this country. It was normal in appearance, both macroscopically and microscopically. The Golgi apparatus in the cells lining the vesicles was not enlarged.

\section{Discussion}

It will be seen that this case differs from those recorded by Blumgart and his colleagues in that total thyroidectomy not only relieved congestive cardiac failure but also restored the heart to normal rhythm. In fact, the removal of a normal thyroid in this case had the same effect as the removal of an abnormal thyroid in a case of thyrotoxicosis. This similarity is the more striking in that in our case normal rhythm returned on the thirteenth day after operation; it is at about this time that auricular fibrillation commonly disappears after thyroidectomy in thyrotoxic cases. Moreover, in our case, as in many cases of thyrotoxic heart disease, cardiac failure only appeared when uncontrolled auricular flutter or fibrillation was present; and it disappeared promptly whenever the heart rate was brought under control. Cardiac failure was dependent on the presence of the disorder of rhythm. In Blumgart's cases, on the other hand, auricular fibrillation was not abolished by total thyroidectomy, and cardiac failure was relieved in spite of the persistence of the disorder of rhythm.

These facts made us consider the possibility that our case was in fact one of thyrotoxicosis. But in our opinion the finding of a thyroid of normal size and normal histological structure excludes this.

If we accept this conclusion, we are faced with the surprising conclusion that thyroidectomy in a man with normal thyroid function has had the same effect on the heart as thyroidectomy in a case of thyrotoxicosis. Our suggested explanation is based on the widely held opinion (Lahey, 1929; Hurxthal, 1931; Lewis, 1931; Andrus, 1932; Rosenblum and Levine, 1933; Mayer and Sittler, 1936; Means, 1937; and Gotta, 1938) that thyrotoxic heart failure is due to a combination of two factors-a primary cardiac disorder and thyroid toxæmia. On this view, thyrotoxicosis cannot by itself cause cardiac failure: it can only make manifest a cardiac disorder that would otherwise remain latent. If we accept the existence of such latent cardiac disorders, it is not difficult to imagine that similar conditions of the heart might exist that are manifest at a normal level of thyroid function but become latent at a low level. This interpretation is supported by our experience of a case of toxic nodular goitre, in which sub- 
total thyroidectomy was followed by the disappearance of auricular fibrillation and later by the development of myxœdema; doses of thyroid extract sufficient to relieve the symptoms of myxœdema led to the reappearance of auricular fibrillation. Swan (1924) had a similar experience. It will be recalled that the patient described here behaved in a similar way, developing paroxysmal auricular fibrillation on 1.5 gr. of thyroid extract a day, but not on $0.5 \mathrm{gr}$. a day. The behaviour of these cases suggests that, in a suitably predisposed heart, auricular fibrillation may be precipitated not only by excessive amounts or by an abnormal type of thyroid hormone but also by the normal hormone in normal quantities.

If this interpretation is correct, then the success of thyroidectomy in our case was due not, as in Blumgart's cases, to a reduction in the work which the heart had to do but to the removal of an agent injurious to the heart. As thyroid extract in full dosage caused the reappearance of auricular fibrillation and omission of the extract was followed by a return to normal rhythm, this agent is presumably the thyroid secretion itself. These considerations make it important to define as far as possible the type of case in which a similar result is likely to be obtained. Among the cases with auricular fibrillation described by Blumgart et al. (1935) there is no record of any in which normal rhythm was restored after total thyroidectomy. All these cases had long histories of cardiac disease and all showed evidence of structural damage of the heart. It seems likely, therefore, that the abolition of auricular fibrillation will not be achieved when it has been long in existence or where it is accompanied by structural damage of the heart. This conclusion is borne out by the experience of Rosenblum and Levine (1933) in cases of thyrotoxicosis with heart failure. They found that of 11 cases with auricular fibrillation and mitral stenosis, only 1 returned to normal rhythm after sub-total thyroidectomy; whereas of 6 cases with auricular fibrillation without evidence of structural damage to the heart, all 6 returned to normal rhythm. Furthermore, the only report of cases similar to ours that we have been able to discover is that of Singer (1937); in both of his cases paroxysmal auricular fibrillation disappeared after total thyroidectomy. Therefore, it seems that the type of case likely to benefit from total thyroidectomy in the way ours has done is one in which auricular fibrillation or flutter is either paroxysmal or not of long duration, and there is no evidence of structural damage of the heart. Such cases are usually regarded as suitable for quinidine therapy; but it may be found that in some instances total thyroidectomy is a more stable and satisfactory alternative. The mortality from the operation is likely to be small, for Berlin's (1935) last 62 total thyroidectomies were performed without fatality, although his cases had gone through long periods of congestive cardiac failure and were therefore poorer operative risks than the type of case we have in mind.

\section{SUMMARY}

A case has been described in which the complete removal of a normal thyroid gland was followed by the disappearance of auricular fibrillation and 
congestive cardiac failure. Auricular fibrillation reappeared when the patient was given $1.5 \mathrm{gr}$. of thyroid extract daily, but disappeared again when the dose was reduced to $0.5 \mathrm{gr}$. daily.

It is suggested that in this case the normal thyroid hormone had the same effect on the heart as has the excessive or abnormal secretion in cases of thyrotoxicosis.

It is suggested that cases of auricular fibrillation or flutter, in which the disorder of rhythm is either paroxysmal or of short duration and there is no evidence of structural damage to the heart, might be expected to benefit in a similar way as the result of total thyroidectomy.

\section{REFERENCES}

Andrus, E. C. (1932). Trans. Ass. Amer. Phys., 47, 47.

Berlin, D. D. (1935). J. Amer. med. Ass., 105, 1104.

Blumgart, H. L., Berlin, D. D., Davis, D., Riseman, J. E. F., and Weinstein, A. A. (1935). Ibid., $104,17$.

Blumgart, H. L., Riseman, J. E. F., Davis, D., and Berlin, D. D. (1933). Arch. intern. Med., $52,165$.

Gotta, G. (1938). Ibid., 61, 860.

Hurxthal, L. M. (1931). Ibid., 47, 167.

Lahey, F. H. (1929). Ann. Surg., 90, 750.

Lewis, W. (1931). Amer. J. med. Sci., 181, 65.

Mayer, C. C., and Sittler, W. W. (1936). J. Amer. med. Ass., 106, 1546.

Means, J. H. (1937). The Thyroid and its Diseases, p. 429.

Rosenblum, H. H., and Levine, S. A. (1933). Amer. J. med. Sci., 185, 219.

Singer, R. (1937). Wien. Klin. Woeh., 50, 1025.

Swan, J. M. (1924). Ann. Clin. Med., 3, 311. 